\title{
Correction to: Interval Return to Play Programs for the Tennis Athlete
}

\author{
loonna Félix ${ }^{1}$ (D) David Dines ${ }^{2} \cdot$ Joshua Dines $^{3}$
}

Published online: 16 July 2021

(C) Springer Science+Business Media, LLC, part of Springer Nature 2021

\section{Correction to: Current Reviews in Musculoskeletal Medicine (2021) 14:185-191 https://doi.org/10.1007/s12178-021-09701-y}

The article Interval Return to Play Programs for the Tennis Athlete, written by Ioonna Félix, David Dines and Joshua Dines, was originally published online on the publisher's internet portal on 03 February 2021 with Open Access under a Creative Commons Attribution (CC BY) license 4.0.

After publication in volume 14, issue 2, page 185-191 the author(s) decided to cancel the Open Access. Therefore, the copyright of the article has been changed on 17 June 2021 to (C) The Author(s), under exclusive license to Springer Science+Business Media, LLC, part of Springer Nature 2021 with all rights reserved.

The original article has been corrected.

Publisher's note Springer Nature remains neutral with regard to jurisdictional claims in published maps and institutional affiliations.

The online version of the original article can be found at https://oi.org/ 10.1007/s12178-021-09701-y

Ioonna Félix

felixi@hss.edu

David Dines

ddinesmd@gmail.com

Joshua Dines

dinesj@hss.edu

1 Hospital for Special Surgery Westside Sports Institute, Hospital for Special Surgery, 610 W. 58th St, New York, NY 10019, USA

2 Sports and Shoulder Service, Hospital for Special Surgery, Suite 106 Earle Ovington Blvd Uniondale, New York, NY, USA

3 Sports Medicine and Shoulder Service, Hospital for Special Surgery Westside Sports Institute, 610 W. 58th St, New York, NY 10019, USA 